\title{
Novel insights into photoisomerization of olefins
}

\author{
Tatsuo Arai, Takashi Karatsu, Hiroaki Misawa, Yasunao Kuriyama, \\ Hiroaki Okamoto, Tatsuro Hiresaki, Hideo Furuuchi, Hualing Zeng, \\ Hirochika Sakuragi, and Katsumi Tokumaru \\ Department of Chemistry, University of Tsukuba, Tsukuba, Ibaraki 305, Japan
}

\begin{abstract}
Aromatic olefins like anthrylethylenes (la-ld) undergo one-way isomerization, which proceeds solely from the cis to trans isomer in very high quantum yields far exceeding unity through adiabatic conversion of initially produced cis triplet $\left({ }^{3} c^{*}\right)$ to trans triplet $\left({ }^{3} t^{*}\right)$ passing through a perpendicularly twisted conformation. This is in remarkable contrast with the well accepted behavior of stilbenes and other olefins. The resulting $3_{t}{ }^{*}$ s have extraordinarily long lifetimes in the order of $10^{2} \mu \mathrm{s}$, and therefore can, in competition with their relatively slow decay, undergo energy transfer to the cis isomer to regenerate $3_{c}{ }^{*}$, thus accomplishing a quantum chain process. The characteristic feature of the potential energy surface was clarified with 2-(ethenyl-2-d)anthracene (le-d), in which there is an energy barrier of $11 \mathrm{kcal} / \mathrm{mol}$ between $3 c^{*}$ and $3 t^{*}$. The mode of isomerization of aromatic olefins, either one-way or two-way, is revealed to be governed by the triplet energy of the aromatic group on one ethylenic carbon as well as by the substituent on the other ethylenic carbon; decrease of the triplet energy of the aromatic group favors the one-way mode, and most olefins in the series of $\mathrm{ArCH}=\mathrm{CHPh}$ prefer the two-way mode compared to the corresponding olefins in the series of $\mathrm{ArCH}=\mathrm{CH}{ }^{\mathrm{t}} \mathrm{Bu}$.
\end{abstract}

\section{INTRODUCTION}

It is well-known that cis and trans isomers of olefins are very stable at room temperature unless exposed to light and might only slowly isomerize on heating at elevated temperatures. This is due to a high energy barrier to be overcome on rotation of the double bond starting from either isomer, as seen in a potential diagram depicted in Fig. 1, where a perpendicularly twisted conformation $\left({ }^{0} \mathrm{p}\right.$ ) is maximum in energy (ref. 1 ).

However, on irradiation many olefins undergo mutual isomerization between their cis and trans isomers, although the conversion does not proceed $100 \%$ to either isomer but give a photostationary mixture of both isomers on starting from either isomer (ref. 1-8). The photoisomerization has been employed in research laboratories as well as in industry to produce useful isomers from their counterparts which are readily available. A practical application is manufacture of fine chemicals like vitamin A, vitamin D, etc (ref. 9).

The mechanism for isomerization in the triplet and singlet excited states has been extensively investigated by many workers with stilbene and its derivatives (ref. 1-8,10-12). An energy diagram well accepted for the isomerization in the triplet manifold is depicted in Fig. 2 (ref. 1-8). Sensitized excitation of cis and trans isomers of olefins gives cis triplets $\left({ }^{*}\right)$ and trans triplets $\left(3_{t}^{*}\right)$, respectively. However, neither $3^{*}$ nor $3^{*}$ is stable and both readily twist around their double bond into the most stable triplet, a perpendicularly twisted triplet $\left(3 \mathrm{p}^{*}\right)$. $3 \mathrm{p}^{*}$ is very close in energy to $0_{\mathrm{p}}$ and undergoes deactivation to ${ }_{\mathrm{p}}$ through intersystem crossing. Then, the resulting $p$ collapses to either cis or trans isomer in the ground state with a certain ratio. Therefore, after irradiation for a sufficient time, the reaction results in a photostationary state comprising of a certain ratio of both isomers.

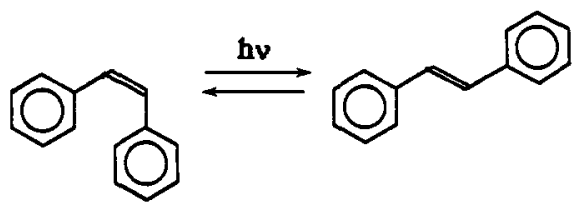

The above energy diagram can explain the observations that both of cis-to-trans and trans-tocis isomerization quantum yields, $\Phi_{c+t}$ and $\Phi_{t \rightarrow c}$, respectively, are generally between 0 and 1 


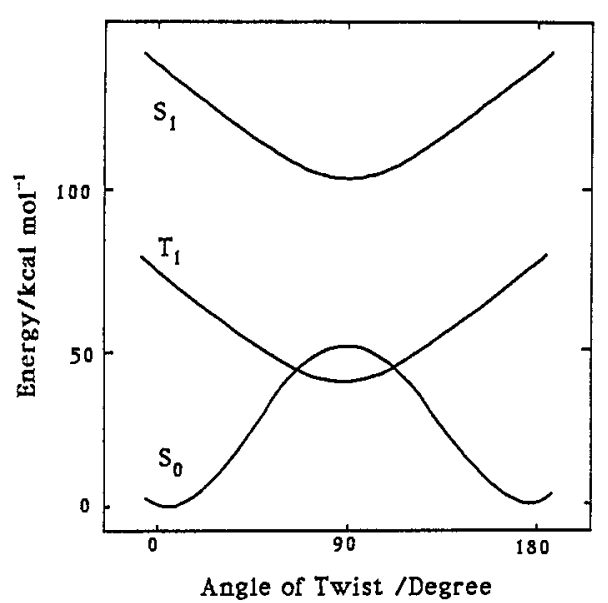

Fig. 1. Calculated potential energy surfaces of ethylene.

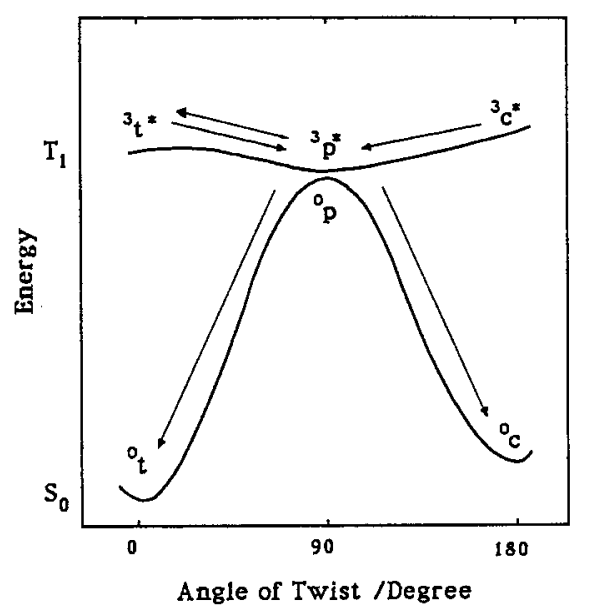

Fig. 2. Proposed potential energy surfaces of stilbene.

(ref. 2,3a,4b,5b,7a,8). To say simply, the mutual isomerization between the two isomers arises from the triplet energy surface, on which ${ }^{3} \mathrm{p}^{*}$ is the most stable and the deactivation to the ground state occurs from $3 \mathrm{p}^{*}$. The triplet energy diagram of stilbene is originated from modifying the results calculated for ethylene, the simplest olefin, by Mulliken (Fig. 1) (ref. 1). For ethylene, although there is no distinction between cis and trans forms in the ground as well as excited states, $p^{*}$ is the most stable in the excited state and a sole deactivation funnel to $0 \mathrm{p}$.

The concept borne out for ethylene and stilbene (ref, 1,2) has been taken to cover all types of olefins. Nobody has doubted that every olefin would undergo the mutual isomerization between its cis and trans isomer, until we made a dramatic finding of one-way isomerization.

\section{ONE-WAY ISOMERIZATION OF AROMATIC OLEFINS}

During the course of our investigation on isomerization of aromatic olefins (ref. 8,13,14), we found that the olefins substituted by a 2-anthryl group and another group, like an alkyl, phenyl, or 2-naphthyl, on one ethylenic carbon and the other, respectively, exert a really dramatic change in photochemical behavior (ref. 15,16). On direct as well as sensitized irradiation, these olefins underwent one-way isomerization from their cis to trans isomers, whereas no reverse isomerization from their trans to cis did not take place even when the trans isomers were excited.

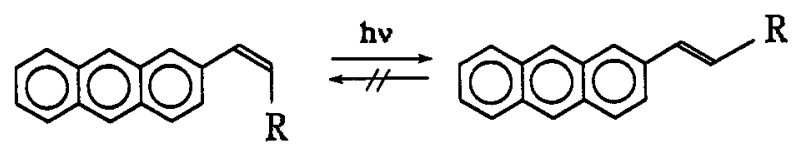

Another feature of the one-way isomerization is that the quantum yield $\Phi_{c \rightarrow t}$ far exceeds unity and increases with increasing concentration of the cis isomer to attain a value of ten or twenty (Fig. 3), indicating clearly that the isomerization takes place through a quantum chain process ( $r$ ef. 15-17). How does the one-way isomerization take place? There is no participation of $3 \mathrm{p}^{*}$ as an important intermediate, since it would give a mixture of both isomers. We have proposed a potential energy diagram depicted in Fig. 4 (ref. 15,16). Thus, ${ }_{3} c^{*}$ resulting from excitation undergoes twisting around the double bond to attain $3 t^{*}$ by passing through a perpendicular conformation. We do not think that an energy minimum is situated at the perpendicular conformation. Therefore, the excited state does not stay at this conformation for a sufficient lifetime to be deactivated to the ground state, and this conformation is only a simple point to be quickly passed. In the proposed energy diagram, $3_{t}{ }^{*}$ resulting from the twisting of $3_{c}^{*}$ undergoes either unimolecular deactivation to $\sigma_{t}$ or bimolecular energy transfer to $0_{c}$ to regenerate $3^{*}{ }^{*}$, which again gives $3^{*}$, thus accomplishing the quantum chain process. On twisting from $3_{c}^{*}$ to $3_{t}^{*}$, the triplet state molecule may overcome an energy barrier in an "across-a-ridge" or "over-a-hump" fashion, depending on the substituent on the $\beta$-ethylenic carbon. To understand the one-way isomerization, one might suppose that in the triplet state the energy minimum would not be at the exactly perpendicular position but slightly shifted to trans side (Fig. 5) (ref. 18,19); however, such a scheme could not explain the observed quantum chain process. 


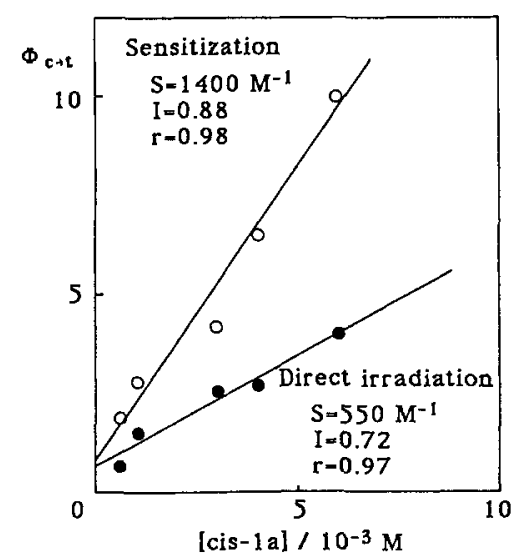

Fig. 3. Cis-isomer concentration effect on $\Phi_{C \rightarrow t}$ in cis-la isomerization in benzene. Photolyses were performed with $313 \mathrm{~nm}$ light and Michler's ketone was used as sensitizer.

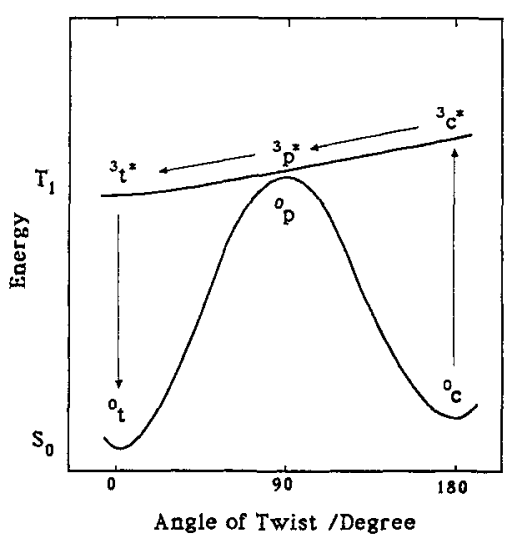

Fig. 4. A possible potential energy surface for one-way isomerization.

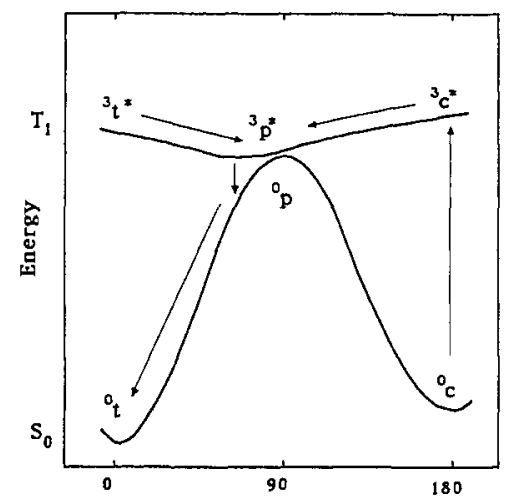

Angle of Twist /Degree

Fig. 5. An improbable potential energy surface for one-way isomerization.

In the 2-anthrylethylenes, the most stable triplet is not $3 \mathrm{p}^{*}$ but $3 \mathrm{t}^{*}$. Transient absorption spectroscopy provided very clear evidence. The twisted triplet $3_{\mathrm{p}}{ }^{*}$ of these olefins should exhibit an absorption as long-wavelength as that due to a 2 -anthrylmethyl radical chromophore, since the remaining chromophore, an alkyl, benzyl, or 2-naphthylmethyl, shows an absorption at shorter wavelengths than the 2-anthrylmethyl radical (Fig. 6 ). However, the absorption of the planar triplet $3_{\mathrm{t}}$ is should depend on the substituent on $\beta$-carbon and should be shifted to longer wavelengths as the substituent becomes well conjugated. Also, $3 p^{*}$ is very close to $O_{p}$ in energy and, therefore, is deactivated facilely to the ground state with a short lifetime, for example, $60 \mathrm{~ns}$ for $3 \mathrm{p}^{*}$ of stilbene (ref. $4 \mathrm{a}$ ), whereas $3_{t}^{*}$ is far from $0_{t}$ in energy and is expected to be alive for a considerably long lifetime. Figure 7 shows the transient absorption spectra obtained by laser flash photolysis (LFP) of the olefins (ref. 16). For every olefin examined, LPF of its cis and trans isomers afforded the same absorptions. Olefins $\underline{1 a}$ and $\underline{1 d}$ carrying an alkyl group on the $\beta$-ethylenic carbon exhibit a strong absorption around $450 \mathrm{~nm}$ and a weak one at $550 \mathrm{~nm}$. Both the absorptions decay with the same lifetime irrespective of the geometry of the starting isomer. On introduction of a phenyl group (1b) at the $\beta$-ethylenic carbon instead of the alkyl group, the strong absorption
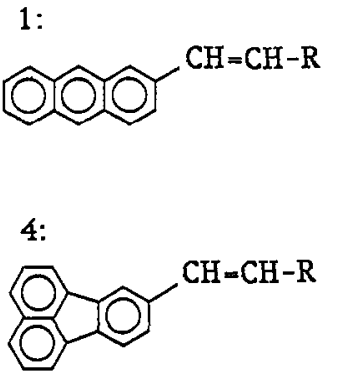

2:<smiles>[R]C=Cc1ccc2ccccc2c1</smiles>

5:

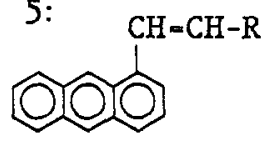

3:

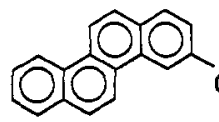

$\mathrm{CH}=\mathrm{CH}-\mathrm{R}$

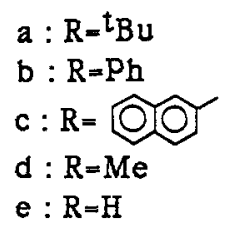

6:

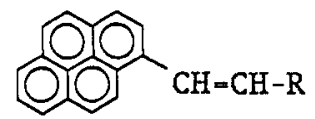

is slightly shifted to longer wavelengths and the absorption at $550 \mathrm{~nm}$ increases in intensity, and another absorption appears at longer wavelengths than $600 \mathrm{~nm}$. Furthermore, introduction of a 2-naphthyl group ( $1 \mathrm{c}$ ) instead of the phenyl group increases intensity of the absorption at $550 \mathrm{~nm}$, shifts slightly the absorption in the $>600 \mathrm{~nm}$ region to longer wavelengths, and increases its intensity to such an extent that this absorption is stronger than those of $\underline{l a}$ and $\underline{l} \underline{d}$ at $450 \mathrm{~nm}$. The transient absorptions of a11 these olefinsexhibitextra-
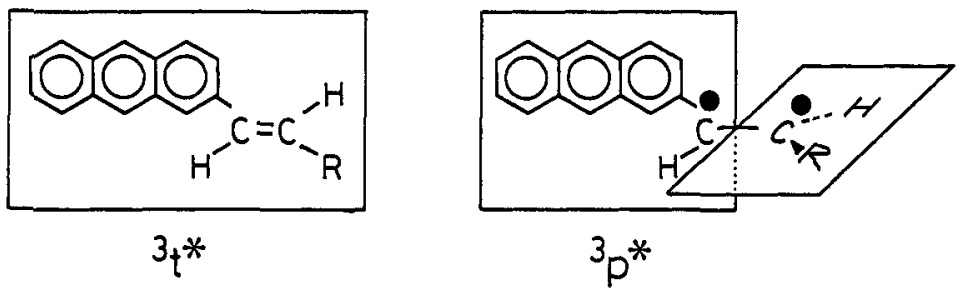

Fig. 6. Pictorial representation of planar $3^{*}$ and perpendicularly twisted $3 \mathrm{p}^{*}$ conformations. 

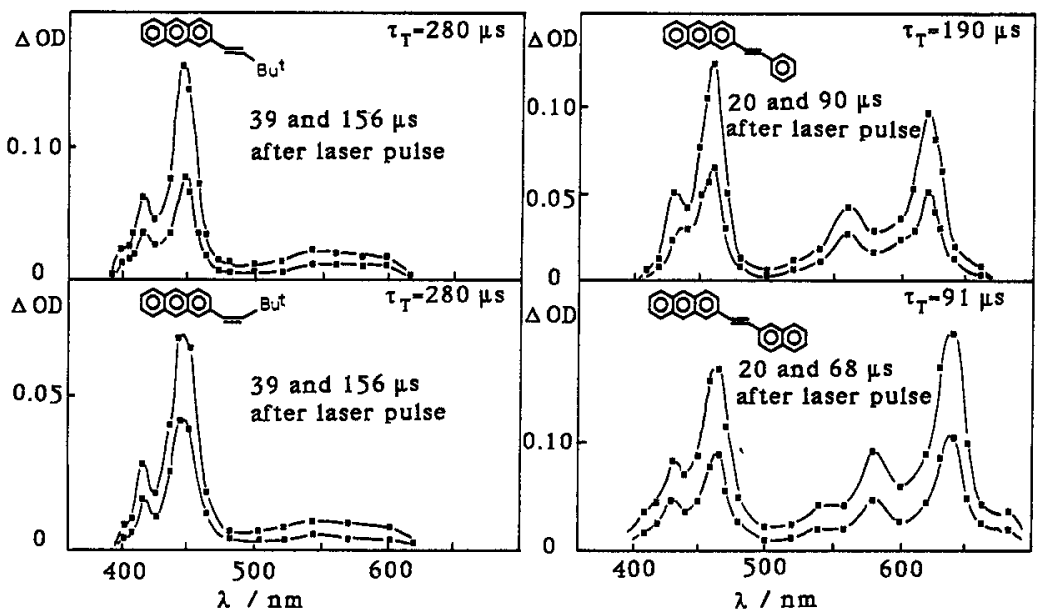

Fig. 7. T-T absorption spectra of 2-anthryletnylenes observed on nitrogen laser $(337 \mathrm{~nm})$ excitation in deaerated benezene.

ordinarily long lifetimes in the order of $10^{2} \mathrm{us}$, which are more than $10^{3}$ times longer than those reported for the twisted triplets of usual olefins like stilbene (ref. 4a).

The above observations that the transient absorptions of olefins la-ld are very much dependent on the structure of olefins and that their lifetimes are extraordinarily longer than those for $3 \mathrm{p}^{*}$ of typical olefins enable us to assign the absorptions to the planar triplets $3_{t}{ }^{*}$. MO (PPP-SCF-SCI) calculations by Wirz (ref. 20) gave the results which agree satisfactorily with our observations (ref. 21 ).

Transient Raman spectroscopy also supports the above assignment. Excitation of both cis- and trans $-1 \mathrm{~b}$ by $355-\mathrm{nm}$ laser followed by Raman probing at $612 \mathrm{~nm}$ resonated with the T-T absorption afforded the same transient Raman spectra which are reasonably assigned to $t^{*}$ of $1 \mathrm{~b}$ (Fig. 8)(ref. 22).

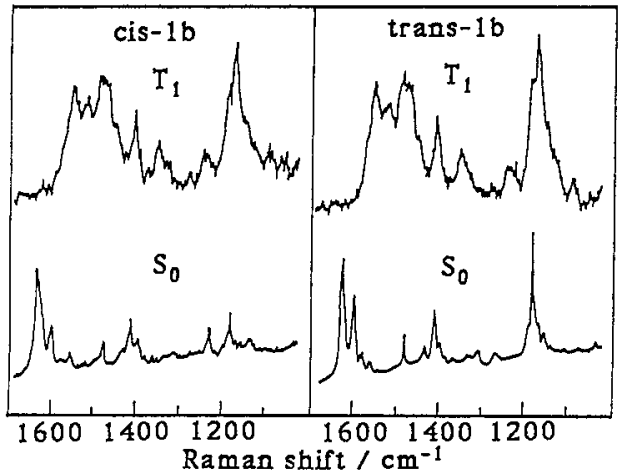

Fig. 8. Raman spectra of $1 \mathrm{~b}$ and transient resonance Raman spectra of triplet 1 b.

\section{QUANTUM CHAIN PROCESS IN ONE-WAY ISOMERIZATION}

According to the proposed mechanism, the quantum yield for isomerization on triplet sensitization is expressed by the following equation:

$$
\Phi \text { Sest }=\Phi{ }_{1 S C}^{\operatorname{Sens}}\left(1+k_{\mathrm{q}} \tau_{T}[\text { cis }]\right)
$$

On direct irradiation, the isomerization of the 2-anthrylethylenes takes place in the triplet manifold but not in the singlet manifold. This is in remarkable contrast with the case of stilbene (ref. 15,16). The cis isomers as well as trans isomers of these olefins exhibit strong fluorescence different in the spectral shape and lifetime (ref. 15,16,21,23). The singlet excited cis isomers undergo either fluorescence emission or intersystem crossing to their triplet states, in which $3 c^{* \prime \prime} s$ isomerize to $3_{t}^{* \prime s}$. The quantum yields for fluorescence emission $\Phi_{f}$ and intersystem crossing $\Phi_{i s c}$ are shown in Table 1 , and their sum for each isomer is nearly unity. The quantum yield for isomerization on direct irradiation is shown by the following equation:

$$
\Phi_{\mathrm{c} i \underline{\text { if }}}=\Phi_{\text {isc }}\left(1+k_{\mathrm{q}} \tau_{\mathrm{T}}[\text { cis }]\right)
$$


Table 1. Yields of singlet oxygen $\left(\Phi_{S O}\right)$ compared with quantum yields of intersystem crossing

\begin{tabular}{|c|c|c|c|c|c|c|c|c|}
\hline \multirow{2}{*}{$\begin{array}{c}\text { Olefin } \\
\text { 2-AnCH=CHR }\end{array}$} & \multicolumn{2}{|c|}{$\Phi_{S O}$} & \multicolumn{2}{|c|}{$\Phi_{\text {isc }}$} & \multicolumn{2}{|c|}{$\Phi_{\mathrm{f}}$} & \multicolumn{2}{|c|}{$\Phi_{\triangle}$} \\
\hline & cis & trans & cis & trans & cis & trans & cis & trans \\
\hline $\begin{array}{l}\mathrm{R}=\mathrm{Ph}(\underline{1 \mathrm{~b}}) \\
\mathrm{R}=2-\mathrm{Np}(\underline{\mathrm{lc}}) \\
\mathrm{R}=\mathrm{t}_{\mathrm{Bu}}(\underline{\mathrm{la}}) \\
\mathrm{R}=\mathrm{Me}(\underline{\mathrm{ld}}) \\
\mathrm{R}=\mathrm{H}(\underline{\mathrm{e}}) \\
\text { Anthracene }\end{array}$ & $\begin{array}{l}0.08 \\
0.10 \\
0.52\end{array}$ & $\begin{array}{l}0.10 \\
0.11 \\
0.38 \\
0.41 \\
0.36 \\
0.58\end{array}$ & $\begin{array}{l}0.17 \\
0.22 \\
0.59\end{array}$ & $\begin{array}{l}0.11 \\
0.12 \\
0.46 \\
0.46 \\
0.49 \\
0.75\end{array}$ & $\begin{array}{l}0.59 \\
0.65 \\
0.41\end{array}$ & $\begin{array}{l}0.87 \\
0.85 \\
0.50 \\
0.46 \\
0.50 \\
0.25\end{array}$ & $\begin{array}{l}0.47 \\
0.45 \\
0.88\end{array}$ & $\begin{array}{l}0.91 \\
0.92 \\
0.76 \\
0.89 \\
0.73 \\
0.77\end{array}$ \\
\hline
\end{tabular}

Table 2. Kinetic values from concentration effect on isomerization quantum yield

\begin{tabular}{|c|c|c|c|c|c|c|}
\hline Olefin & Sensitizer & $\begin{array}{l}\text { Slope } \\
/ \mathrm{dm}^{3} \mathrm{~mol}\end{array}$ & Intcpt & $\begin{array}{l}\text { Slope/Intcpt } \\
/ \mathrm{dm}^{3} \mathrm{~mol}^{-1}\end{array}$ & $\begin{array}{r}\tau \mathrm{T} \\
/ \mu \mathrm{s}\end{array}$ & $\begin{array}{c}\mathrm{k}_{\mathrm{q}} \\
/ \mathrm{dm}^{3} \mathrm{~mol}^{-1} \mathrm{~s}^{-1}\end{array}$ \\
\hline cis-1a & $\overline{M K}$ & $\begin{array}{r}550 \\
1400\end{array}$ & $\begin{array}{l}0.72 \\
0.88\end{array}$ & 760 & $\begin{array}{l}280 \\
280\end{array}$ & $\begin{array}{l}2.7 \times 10^{6} \\
5.0 \times 10^{6}\end{array}$ \\
\hline cis-1b & $\overline{\mathrm{BA}}$ & $\begin{array}{r}4200 \\
11000\end{array}$ & $\begin{array}{l}0.43 \\
1.6\end{array}$ & 9800 & $\begin{array}{l}190 \\
190\end{array}$ & $\begin{array}{l}5.2 \times 10^{7} \\
5.8 \times 10^{7}\end{array}$ \\
\hline cis-1c & $\overline{\mathrm{BA}}$ & $\begin{array}{r}3200 \\
16000\end{array}$ & $\begin{array}{l}0.38 \\
1.4\end{array}$ & 8400 & $\begin{array}{l}90 \\
90\end{array}$ & $\begin{array}{l}9.2 \times 10^{7} \\
1.7 \times 10^{8}\end{array}$ \\
\hline
\end{tabular}

Intcpt: Intercept. MK: Michler's ketone.

BA: Biacetyl.

Table 3. Isomerization quantum yields of $1 \mathrm{a}$ on dye sensitized irradiation

\begin{tabular}{lcccc}
\multicolumn{1}{c}{ Dye } & $E_{\mathrm{T}} / \mathrm{kcal}$ mol & $\Phi_{\mathrm{C} \rightarrow \mathrm{t}}$ & $\Phi_{1 \mathrm{Sc}}^{\text {Dye }}$ & $\Phi_{\mathrm{C} \rightarrow \mathrm{t}} / \Phi_{\mathrm{I} \mathrm{SC}}^{\mathrm{Dy}}$ \\
Methylene blue & 34 & 0 & 0.52 & 0 \\
Thionine & 39 & 0 & 0.55 & 0 \\
Rose bengal & $39.5-42$ & 3.7 & 1.0 & 3.7 \\
Eosin Y & $43-46$ & 15 & 0.64 & 23 \\
Erythrosin & $43-45$ & 24 & 1.0 & 24 \\
Fluorescein & $45-48$ & 1.1 & 0.05 & 22 \\
Acridine orange & 49 & 0.56 & 0.10 & 5.6 \\
Proflavine & 51 & 1.9 & 0.46 & 4.1 \\
- & & & &
\end{tabular}

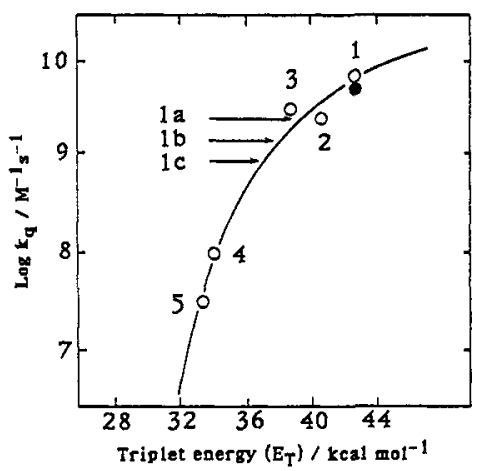
Fig.9.Estimationoftriplet energies ( $E_{T}$ ) of la-lcfrom the relation of $\mathrm{E}_{\mathrm{T}}$ and quenching rate constants $\left(\mathrm{k}_{\mathrm{q}}\right)$ by azulene.
1. anthracene (the filled circle was determined in this work);
2. dibenzo[b,h ]pyrene;
3. 5-methyldibenzo[b,h]pyrene;
4. 5,8-dimethyldibenzo [b,h]pyrene;
5. dibenzo[b,g]pyrene.

On direct as well as sensitized irradiation, the quantum yield linearly increases with increasing cis isomer concentration as depicted in Fig. 3. Dividing the slopes by the intercepts affords $\mathrm{k}_{\mathrm{q}} \tau_{\mathrm{T}}$ values, which give the $\mathrm{k}_{\mathrm{q}}$ values when combined with the determined $\tau_{\mathrm{T}}$ values (Table 2). The $k_{\mathrm{q}}$ values vary from the order of $10^{6}$ to $10^{8} \mathrm{dm}^{3} \mathrm{~mol}^{-1} \mathrm{~s}^{-1}$ depending on the substituents, an alkyl, phenyl, and 2-naphthyl (ref. 15,16,18). These values mean that the energy transfer from ${ }^{3}{ }^{*}$ to ${ }_{c}$ is slightly endothermic. It is not so usual to see slightly endothermic energy transfer taking place effectively. It should be emphasized that this is solely due to the extraordinarily long $3_{t}^{*}$ lifetimes, during which $3_{t}^{*}$ can transfer energy to ${ }_{c}$ in competition with unimolecular deactivation.

The triplet excitation energies $\left(E_{T}\right)$ of the trans forms of olefins, $1 \mathrm{a}, \underline{1 b}$, and $\underline{1 c} \mathrm{can} b e$ estimated from their weak phosphorescence (in EPA at $77 \mathrm{~K}$ ) as $42.5,41.0$, and $39.8 \mathrm{kca} 1 / \mathrm{mol}$, respectively. The triplet energies for the cis isomers were estimated by examining the effect of triplet dye sensitizers with varying energies as listed in Table 3 (ref. 18). Table 3 shows that cis-la can be sensitized by sensitizers with triplet energies higher than $42 \mathrm{kcal} / \mathrm{mol}$. 
To estimate the triplet energies of the trans isomers, the rate constants for quenching of their triplet states by azulene ( $\mathrm{E}_{\mathrm{T}} 39.8 \mathrm{kcal} / \mathrm{mol}$ ) (ref. 24) were determined since the triplet states generally are less efficiently quenched by azulene when their energies become closer to that of azulene. The observed rate constants for $3 t^{* 1}$ s of la-lc are plotted against the triplet energies along with the quenching rate constants reported for the wellknown triplet states (Fig. 9)(ref. 25). The results indicate that $3^{*}$ lies 40,38 , and 37 $\mathrm{kcal} / \mathrm{mol}$ above $\mathrm{O}_{\mathrm{t}}$ for $\underline{\mathrm{la}}, \underline{\mathrm{b}}$, and $\underline{\mathrm{lc}}$, respectively (ref. 18). The $\beta$-substituent dependence of the triplet energy is in good agreement with the phosphorescence results.

\section{TRIPLET ENERGY SURFACES OF ONE-WAY ISOMERIZING OLEFINS}

In the one-way isomerization, ${ }^{3} c$ * undergoes twisting around the double bond to give ${ }^{3} t$; however, a problem arises whether the triplet energy surface decreases monotonically in energy from $3 c^{*}$ to $3_{t}^{*}$ or involve an energy barrier around the perpendicular conformation. To solve this problem, we investigated photochemical behavior of 2 -vinylanthracene (le) and its deuterated derivative (le-d).

On benzil-sensitized irradiation in benzene at $7{ }^{\circ} \mathrm{C}$, trans-le-d did not efficiently isomerize into the cis isomer. However, the isomerization was clearly observed above $16{ }^{\circ} \mathrm{C}$ (ref. 26). The observed $\Phi_{\rightarrow}$ values are extremely low compared with those for stilbenes and styrenes (ref. 2, 4b,5b,7a,8), and increase with temperature. However, the lifetime of the triplet state was essentially independent of temperature. These findings clearly indicate that the triplet trans-le-d isomerizes to the triplet cis-le-d in an adiabatic way by overcoming an energy barrier at the perpendicular conformation as the transition state. This novel type of photochemical isomerization effected by heat can be termed as "across-a-ridge" or "over-ahump" isomerization.

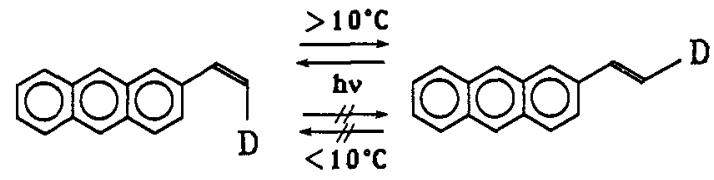

The isomerization quantum yield $\Phi_{t \rightarrow c}$ is expressed by the following equation:

$$
\begin{aligned}
\Phi_{t \rightarrow c} & =\Phi_{S T} \Phi_{E T}\left[k_{r} /\left(k_{d}+k_{r}\right)\right]\left[1-k_{r} /\left(k_{d}+k_{r}\right)\right] \\
& =\Phi_{S T} \Phi_{E T} k_{r} k_{d} /\left(k_{d}+k_{r}\right)^{2},
\end{aligned}
$$

where $k_{r}$ and $k_{d}$ are the rate constants for $C=C$ bond rotation leading to the isomerization between the triplet trans-1e-d and cis-1e-d, and for their deactivation, respectively. The $k_{r}$ and $k_{d}$ values must be the same for the two isomers. $\Phi_{S T}$ and $\Phi_{E T}$ represent the quantum yields for intersystem crossing of singlet excited sensitizer and for energy transfer from the triplet sensitizer to trans-le-d, respectively.

An assumption that $\Phi \mathrm{ST}_{\text {and }} \Phi{ }_{\mathrm{ET}}$ are independent of temperature enables us to estimate $\mathrm{k}_{\mathrm{r}}$

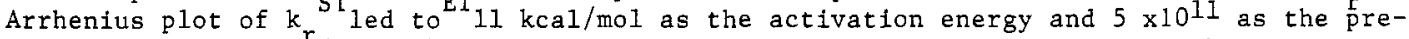
exponential factor. ${ }^{\mathrm{r}}$ (Fig 10 ). The large activation energy barrier inhibits the twisting of $\mathrm{C}=\mathrm{C}$ bond and, therefore, the decay should occur from the planar conformation of the triplet. The planar triplet is nearly $42 \mathrm{kcal} / \mathrm{mol}$ above the ground state as determined by its phosphorescence and the quenching rate constant by azulene and perylene. These results allow us to draw potential energy surface of le as shown in Fig. 11.

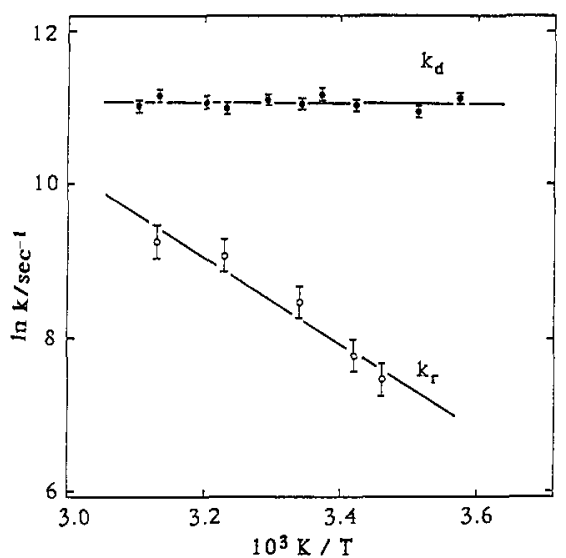

Fig. 10. Arrheniusplots of rate constants for $\mathrm{C}=\mathrm{C}$ bond rotation $\left(k_{r}\right)$ and deactivation $\left(k_{d}\right)$.

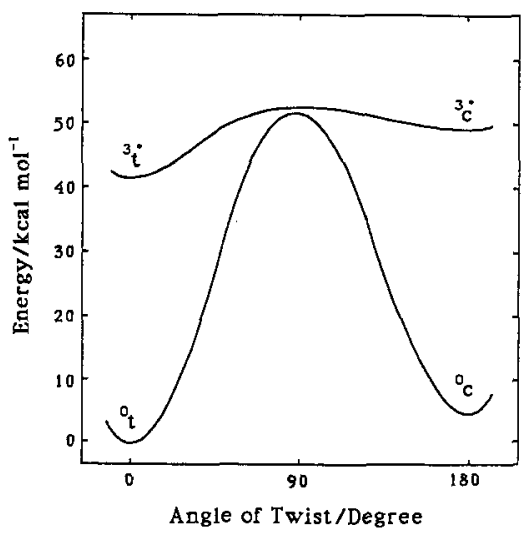

Fig. 11. A possible potential energy surface for over-a-hump isomerization. 
The luminescence of singlet oxygen, $\mathrm{O}_{2}\left({ }^{1} \Delta_{\mathrm{g}}\right)$, produced on quenching of the triplets of 2-anthrylethylenes by oxygen has provided valuable informations about their triplet states, not only the most stable $3_{t}^{*}$ but also the profile of the triplet potential energy surfaces.

Generally, triplet states are quenched by oxygen (ref. 27). When the triplet takes a conformation of $3 \mathrm{p}^{*}$, the quenching may take place through acceleration of intersystem crossing to $\mathrm{O}_{\mathrm{p}}$ (spin exchange interaction) with a rate constant of $(6-9) \times 10^{9} \mathrm{dm}^{3} \mathrm{~mol}^{-1} \mathrm{~s}^{-1}$ in benzene at room temperature ( $3 / 9$ of the diffusion-controlled rate constant, $k_{d i f}$ ) without producing singlet oxygen since $3_{\mathrm{p}}^{*}$ is very close in energy to $0_{\mathrm{p}}$. However, when the olefin triplet has a large population of $3 t^{*}$, the quenching by oxygen proceeds through energy transfer with a rate constant of $(2-3) \times 10^{\prime} \mathrm{dm}^{3} \mathrm{~mol}^{-1} \mathrm{~s}^{-1}$ ( $\left.\mathrm{k}_{\mathrm{dif}} / 9\right)$ to produce singlet oxygen with a high efficiency since $3 t^{*}$ lies in energy far above $t$ (ref. 4a,12,13c). Therefore, the determination of the efficiency for singlet oxygen production provides the population of the triplet state at $3_{t *}^{*}(r e f .28)$.

The quantum yields for singlet oxygen production determined for the 2-anthrylethylenes are listed in Table 1 (ref. 23). The observed values are all more than nealy 0.5 , and particularly high for the trans isomers and cis-la, indicating that the triplet states of these olefins take high populations of $\mathrm{t}^{* *}$, particularly on excitation of their trans isomers. On excitation of the cis isomers, oxygen was found to reduce $\Phi_{c \rightarrow t}$ remarkab1y for $1 \mathrm{a}$. If $3_{c}{ }^{*}$ is not located at an energy minimum but at the highest level on a triplet potential energy surface simply decreasing in energy to $\mathrm{t}^{*}, 3_{\mathrm{c}}$ would not have a lifetime enough to be quenched by oxygen.

The observation of the across-a-ridge or over-a-hump isomerization in 2-vinylanthracene le enables us to suppose that the perpendicular conformation of the triplet la is located $\overline{10}$ $\mathrm{kcal} / \mathrm{mol}$ higher in energy than $3_{t}^{* *}$ and also several kcal/mol higher than $3 \mathrm{c}^{*}$ (Fig. 11). In cis-la the bulky t-butyl group induces rotation of the anthryl group around the single bond connecting to the double bond, resulting in a less conjugated triplet similar to an anthracene triplet. Therefore, the observed high value of $\Phi_{\Delta}$ for cis-1a seems to indicate that $3_{c}^{*}$ as well as the resulting $3_{t}^{*}$ is quenched by oxygen to produce singlet oxygen.

The relatively low $\Phi_{\Delta}$ values for cis-lb and cis-lc indicate participarion of the spin exchange interaction in the quenching by oxygen. This can be interpreted in terms of some stabilization of 1,2-biradicaloid twisted geometries through benzyl-type conjugation with the phenyl or 2-naphthyl group.

\section{FACTORS GOVERNING THE MODES OF ONE-WAY AND TWO-WAY ISOMERIZATION}

As described above, the 2-anthrylethylenes undergo the one-way isomerization. The next problem is what factors govern the mode of isomerization, either one-way or two-way. For two-way isomerizing olefins, we have already classified their triplet potential energy surfaces into three types, classes A, B, and C, on the basis of the effects of azulene and oxygen on the photostationary isomer ratio (Fig. 12)(ref. 13b). Introduction of an aromatic group with a low triplet energy like a naphthalene molety stabilizes ${ }^{*}{ }^{*}$, and increases the population of $3 \mathrm{t}^{*}$, which is equilibrated with ${ }^{3} \mathrm{p}$, although the deactivation still takes place solely from $3 \mathrm{p}^{*}$. The mechanism for one-way isomerization of the 2-anthrylethylenes is taken to indicate that introduction of an aromatic group with a very low triplet energy like an anthracene moiety highly stabilizes the planar triplets $3_{t}^{*}$ and $3_{c}^{*}$, particularly, $3_{t *}$. As a result, a deep energy minimum at the perpendicular conformation tends to disappear.

(1)-CH=CH-R

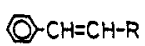

R: - Me, - But

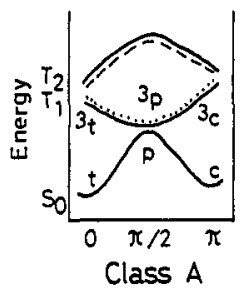

Azutene

Oxygen

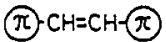

(O) $\mathrm{CH}=\mathrm{CH}-\mathrm{O}$
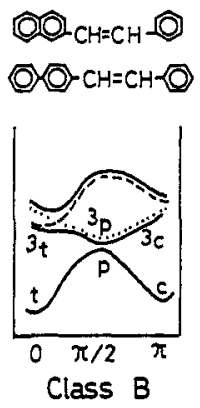

effective
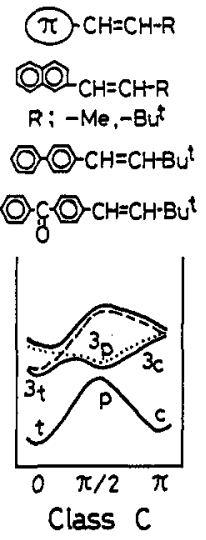

etfective
Fig. 12.

Classification of triplet energy surfaces of aromatic olefins.

$\cdots$ : ethylenic triplet $\psi_{e}$,

-- : aromatic triplet $\psi_{\mathrm{a}}$. 
Table 4. Modes of isomerization and triplet lifetimes of $\mathrm{ArCH}=\mathrm{CHR}$

\begin{tabular}{|c|c|c|c|}
\hline \multirow{2}{*}{ Ar } & \multirow{2}{*}{$\begin{array}{l}\mathrm{E}_{\mathrm{T}} \text { of } \mathrm{ArH} \\
/ \mathrm{kcal} \mathrm{mol}^{-1}\end{array}$} & \multicolumn{2}{|c|}{$\tau_{\mathrm{T}} / \mu \mathrm{s}\left(\lambda_{\max }^{\mathrm{T}}-\mathrm{T} / \mathrm{nm}\right)$} \\
\hline & & $\mathrm{R}=\mathrm{t}_{\mathrm{Bu}}$ & $\mathrm{R}=\mathrm{Ph}$ \\
\hline Pheny 1 & 84.3 & two-way & $\begin{array}{c}\text { two-way } \\
0.063(<360)\end{array}$ \\
\hline 2-Naphthy1 & 60.9 & $0.13^{\text {two-way }}(420,570)$ & $\begin{array}{c}{ }^{\text {two-way }} \\
0.14^{(400,500)}\end{array}$ \\
\hline 3-Chrysenyl & 56.6 & $\begin{array}{l}\text { one-way } \\
0.36(600)\end{array}$ & $\begin{array}{c}\text { two-way } \\
0.14(<400)\end{array}$ \\
\hline 8-F1uorantheny 1 & 54.2 & $25 \stackrel{\text { one-way }}{(440,580)}$ & $0.47^{\text {two-way }}(480,600)$ \\
\hline I-Pyrenyl & 48.2 & & $16 \begin{array}{l}\text { two-way } \\
(480,580)\end{array}$ \\
\hline 2-Anthry1 & 42.0 & $\begin{array}{c}\text { one-way } \\
280(450,540)\end{array}$ & $190(460,620)$ \\
\hline
\end{tabular}

Generally, the triplet energy surfaces of the aromatic olefins can be drawn by an "ethylenic" triplet $\psi_{e}$ with an energy minimum at the twisted geometry and an "aromatic" triplet $\psi_{a}$ with energy minima at the planar geometries (ref, 6a,13b,29). For stilbene, $\psi_{e}$ dominates at $3 p^{*}$ (ref. 6a,30); however, at $3_{t}{ }^{*} \psi_{e}$ and $\psi_{a}$ interact to result in stabilization of $3_{t}{ }^{*}$ to some extent. In $2-\mathrm{NpCH}=\mathrm{CH}^{t} \mathrm{Bu}(\underline{2 a})$, the naphthyl group much lowers $\psi_{\mathrm{a}}$ and stabilizes $3_{t}^{*}$ to give a nearly equimolar equilibrium mixture of $3^{*}$ and $3_{\mathrm{p}}^{*}$. Introduction of a 2 -anthry1 group on ethylene as in 2-vinylanthracene extremely stabilizes $\psi_{a}$ at all the conformations, and no avoided crossing occurs even at the perpendicular conformation. Therefore, the triplets mainly populate on the anthracene nucleus and the twisted geometry is a transition state in the isomerization. The situation is nearly the same when 2-vinylanthracene is substituted by an alkyl group at the terminal carbon.

An attempt has been done to examine the effects of aromatic substituents with the triplet energies between those of naphthalene and anthracene. Table 4 briefly summarizes the results (ref. 31-36). In a series of aromatic olefins carrying an alky1 (t-buty1) group at the $\beta$-ethylenic carbon, those substituted by an aromatic group with the triplet energy lower than that of the 2-naphthy1 group (2a), i.e., the 3-chrysenyl (3a), 8-fluoranthenyl (4a), and 1 -anthryl derivative ( $\underline{5 a})$, brought about the cistrans one-way isomerization involving the quantum chain process as observed in the quantum yields $\Phi$ 's which increased with increasing cis-isomer concentration. The triplet states of these olefins are mostly ascribed to $3_{t}^{*}$. They exhibited transient absorption spectra at longer wavelengths than those of the parent aromatic hydrocarbons due to their conjugation with the ethylenic linkage. However, in another series of aromatic olefins, the $\beta$-ethylenic carbon of which is substituted by a phenyl group, all the aromatic groups, including 1-pyrenyl, having triplet energies higher than that of the anthryl group led to the two-way isomerization (Table 4). 3-Styrylchrysene (3b) exhibited a transient absorption mostly ascribable to $3^{*}{ }^{*}$ which is equilibrated with $3_{t^{*}}$; the absorption appeared at shorter wavelengths than its counterpart with a $t$-butyl group $(\underline{3 a})$. However, 8-styrylfluoranthene $(\underline{4 b})$ and $1-$ styrylpyrene $(\underline{6 b})$ showed the absorption mainly due to $3_{t}^{*}$. These results indicate that the equilibration between $3 \mathrm{p}^{*}$ and $3^{*}$ depends on the triplet energy of the larger aromatic group.

In the series of $\mathrm{ArCH}=\mathrm{CH}^{t} \mathrm{Bu}$, the aromatic triplet $\psi_{\mathrm{a}}$ tends to predominate at the ${ }^{3} \mathrm{t}^{*}$ and twisted conformations with decreasing triplet energy of the aryl group. On the other hand, in the $\mathrm{ArCH}=\mathrm{CHPh}$ series, the phenyl group considerably stabilizes $\psi_{e}$ to make it interact with $\psi_{\mathrm{a}}$ at the twisted geometry, even if $\psi_{\mathrm{a}}$ is significantly stabilized, leading to the avoided crossing between them. As a result, the twisted conformation of ArHC.-CHR is more stabilized in the case where $R=$ phenyl than is in the case where $R=t_{B u}$. Therefore, the presence of a phenyl group puts an energy minimum at the twisted conformation resulting in equilibrium between $3_{t}^{*}$ and $3_{\mathrm{p}}^{*}$ in $\mathrm{ArCH}=\mathrm{CHPh}$.

The equilibrium constant $K_{t p}\left(=\left[{ }^{3} p^{*}\right] /\left[{ }^{3} t^{*}\right]\right)$ between ${ }^{3} p^{*}$ and $3 t^{*}$ is estimated by several methods. A method often employed is determination of the rate constant for quenching of the 
triplet state by azulene (Az). Usually, planar triplet states like $3^{*}$ is efficiently quenched by azulene with a diffusion controlled rate constant, $\mathrm{k}_{\mathrm{Az}},(7-10) \times 10^{9} \mathrm{dm}^{3} \mathrm{~mol}^{-1} \mathrm{~s}^{-1}$ in benzene at room temperature, when they have a triplet energy sufficiently higher than that of azulene $(39.8 \mathrm{kcal} / \mathrm{mol})$. On the other hand, $3 \mathrm{p}^{*}$ is not quenched by azulene, since ${ }^{3} \mathrm{p}^{*}$ does not have a triplet energy enough to excite azulene. Therefore, a triplet state composed of $3 t^{*}$ and $3 \mathrm{p}^{*}$ gives a quenching rate constant, $\mathrm{k} / \mathrm{bs}$, between 0 and $\mathrm{k}_{\mathrm{Az}}$ depending on the ratio of $3_{t}^{*}$,

$$
\mathrm{k}_{\mathrm{Az}}^{\mathrm{bs}}=\mathrm{k}_{\mathrm{Az}} /\left(1+\mathrm{K}_{\mathrm{tp}}\right)
$$

In the series of $\mathrm{ArCH}=\mathrm{CHPh}$, with decreasing triplet energy of the aryl group, 2-naphthyl, 3chryseny $1,8-f 1$ uoranthenyl, and 1-pyrenyl, the $K_{t p}$ value was reduced in the same order as $1.4-2.2$ (ref. 12), $1.4,0.5$, and $<0.1$. These values reflect decreasing stability of $3 \mathrm{p}^{*}$ relative to $3^{*}$.

Among the aromatic olefins examined, 1-styrylpyrene (6b) exhibited interesting behavior as a border between the two-way and one-way modes; the overall mode is two-way, but $\Phi_{c \rightarrow t}$ increases with increasing cis-isomer concentration. These features indicate that the deactivaion of the triplet state occurs from both $3 \mathrm{p}^{*}$ and $3_{\mathrm{t}}{ }^{*}$. The former gives a mixture of $0_{c}$ and $O_{t}$ and the latter affords solely $O_{t}$ with concurrent regeneration of $3_{c}{ }^{*}$ by energy transfer to $0_{c}$.

The facts that the borderline to distinguish between the two-way and one-way modes is found between the naphthyl ( $E_{\mathrm{T}} 61 \mathrm{kcal} / \mathrm{mol}$ ) and the chrysenyl derivative (ET 57 ) for the $\mathrm{ArCH}=\mathrm{CH}^{\mathrm{t}} \mathrm{Bu}$ series and at the pyrenyl derivative $\left(E_{\mathrm{T}} 48\right)$ for the $\mathrm{ArCH}=\mathrm{CHPh}$ series provide profiles of the triplet potential energy surfaces of these olefins. With decreasing triplet energy of the aromatic group, $3_{t}{ }^{*}$ may be more stabilized in energy than ${ }^{3} \mathrm{p}^{*}$; however, in PyrCH=CHPh ( $6 \mathrm{~b}) 3_{\mathrm{p}}^{*}$ and $3_{t}^{*}$ are still in equilibrium and both are deactivated to the ground state. As described previously, quenching of the triplet state of AnthCH $=\mathrm{CHNp}$ ( $1 \mathrm{c}$ ) by oxygen afforded a relatively low yield of singlet oxygen. This indicates that even substitution by an anthryl group may bring about a shallow minimum at the perpendicularly twisted geometry on the triplet energy surface so that this geometry can interact with oxygen to be deactivated.

Moreover, behavior of the triplet states was found to be different between 1- and 2-anthry1ethylenes to some extent. Direct and sensitized irradiation of $1-\mathrm{AnthCH}=\mathrm{CH}^{\mathrm{t}} \mathrm{Bu}(5 \mathrm{a})$ and 1Anth $\mathrm{CH}=\mathrm{CHPh}(\mathrm{5b})$ resulted in the one-way isomerization. The quantum yields were higher than unity on sensitized irradiation. However, their quantum chains are shorter than the corresponding 2-anthryl derivatives. The former triplet states exhibit their T-T absorption at shorter wavelengths than the latter, and their triplet energies $(40.7$ and $38.8 \mathrm{kcal} / \mathrm{mol}$ for $5 \mathrm{a}$ and $5 \mathrm{~b}$, respectively at the trans planar geometry) were lower than those for the latter. The spin densities of triplet anthracene are higher at the 1-position than at the 2-position. Accordingly, the conjugation in the triplet state between the anthryl group and the ethylenic part must be larger in the 1-anthryl derivatives than is in the 2-anthryl derivatives. The more efficient conjugation in the 1 -anthrylethylenes results in more endothermic energy transfer from $3_{t}{ }^{*}$ to $O_{c}$ than 2-anthrylethylenes.

Finally, it is to be noted that the finding of one-way isomerization which had never been supposed to take place even by theoreticians has not only developed a novel aspect of the mechanism for photoisomerization but also provided a more general view to cover the conventional two-way isomerization and the new type of isomerization. This finding may also develop novel aspects of photochemical changes of biomolecules and amplification of effects of photons (ref. 37). It is very encouraging for chemists to recognize that a concept borne out by precise works for some seemingly typical compounds, may not completely cover all compounds of similar type and that even slight variation of molecular structure can bring about an innovative concept.

\section{Acknowledgement}

The authors thank the Ministry of Education, Science, and Culture, Japan for financial support of this work under Grant-in-Aid for Scientific Research (No. 59540251 for K. T. and No. 61740242 for T. A.) and Special Project Research (Nos. 61123001 and 62113001 for K. T.), and the University of Tsukuba for the partial support under Project Research. The authors thanks are also due to Dr. Shigero Oishi for collaboration in transient spectroscopy, Professors Hiroo Hamaguchi and Mitsuo Tasumi, the University of Tokyo for colloboration in transient Raman spectroscopy, Professor Michael Rodgers, Bowling Green University, Ohio for kind arrangements for use of the instrument to detect singlet oxygen luminescence at CFKR, the University of Texas, Austin, Texas, Professor Jacob Wirz, University of Basel for calculations of transient absorption, and many scientists particularly in the field of photoisomerization for helpful discussions. 


\section{REFERENCES}

1. a. A. J. Merer and R. S. Mulliken, Chem. Rev., 63, 639 (1969).

b. R. S. Mulliken, J. Chem. Phys., 66, 2448 (1977).

2. a. G. S. Hammond, J. Saltie1, A. A. Lamola, N. J. Turro, J. S. Bradshaw, D. O. Cowan, R.

C. Counse11, V. Vogt and C. Dalton, J. Am. Chem. Soc., 86, 3197 (1964).

b. G. S. Hammond, D. E. Demeyer, and J. L. R. Williams, ibid., 91, 5180 (1969).

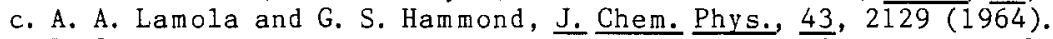

3. a. D. Gegiou, K. A. Muszkat, and E. Fischer, J. Am. Chem. Soc., 90, 3907 (1968).

b. V. Krongauz, N. Caste1, and E. Fischer, J. Photochem., 39, 285 (1987).

c. K. Sandros and H. -D. Becker, J. Photochem. 39, 301 (1987).

4. a. H. Görner and Schulte-Frohlinde, J. Phys. Chem. 85, 1835 (1981).

b. D. Schulte-Frohlinde and H. Görner, Pure Appl. Chem., 51, 279 (1979).

c. H. Gorner and Schulte-Frohlinde, J. Photochem., 8 , 91 (1978).

5. a. J. Saltiel, S. Ganapathy, and C. Werking, J. Phys. Chem., 91, 2755 (1987).

b. J. Saltiel and J. L. Charlton, in Rearrangement in Ground and Excited States, ed. by P. de Mayo, Vol. 3, Academic Press, New York (1980), p. 25.

c. J. Saltiel, G. R. Marchand, E. Kirkor-Kaminska, W. K. Smothers, W. B. Mueller, and J. L. Charlton, J. Am. Chem. Soc., 106, 3144 (1984).

d. J. Saltiel, A. D. Rousseau, and B. Thomas, J. Am. Chem. Soc., 105, 7631 (1983).

6. a. R. Bonneau, J. Photochem., 10, 439 (1979).

b. S. Lazare, R. Lapouyade, and M.-P. Robert, Nouv. J. Chim., 8, 407 (1984).

c. S. Lazare, R. Bonneau, and R. Lapouyade, J. Phys. Chem., 88, 18 (1984).

7. a. R. A. Caldwe11, G. W. Sovocool, and R. J. Peresie, J. Am. Chem. Soc., 95, 1496 (1973),

b. R. A. Caldwell and C. V. Cao, J. Am. Chem. Soc., $104,6174(1982)$.

8. T. Arai, H. Sakuragi, and K. Tokumaru, Bul1. Chem. Soc. Jpn., 55, 2204 (1982).

9. a. V. Malatesta, C. Willis, and P. A. Hacckett, J. Am. Chem. Soc, 103, 6781 (1981).

b. H. J. Hansen and K. Pfoertner, Eur. Pat. Appl., EP 130509 (1985).

10. R. M. Hochstrasser, Pure Appl. Chem.. 52, 2683 (1979).

11. M. Sụmitani and K. Yoshihara, J. Chem. Phys., 76, 738 (1982).

12. H. Görner, D. W. Eaker, and J. Saltie1, J. Am. Chem. Soc., 103, 7164 (1981).

13. a. T. Arai, H. Sakuragi, and K. Tokumaru, Chem. Lett., 1335(1980).

b. T. Arai, T. Karatsu, H. Sakuragi, and K. Tokumaru, Chem. Lett., 1377 (1981).

c. T. Arai, H. Sakuragi, K. Tokumaru, Y. Sakaguchi, J. Nakamura, and H. Hayashi, Chem. Phys. Lett., 98, 40 (1983).

14. K. Tokumaru and T. Arai, Kagaku (Chemistry), 37, 235 (1982).

15. T. Arai, T. Karatsu, H. Sakuragi, and K. Tokumaru, Tetrahedron Lett., 24,2873 (1983).

16. T. Karatsu, T. Arai, H. Sakuragi, and K. Tokumaru, Chem. Phys. Lett., 115,9 (1985).

17. T. Karatsu, H. Sakuragi, and K. Tokumaru, Kagaku (Chemistry), 39, 201 (1984).

18. T. Karatsu, Thesis (University of Tsukuba, 1985).

19. T. Arai and K. Tokumaru, Yuki Gosei Kagaku Kyokaishi (J. Synth. Org. Chem. Jpn), 44,999 (1986).

20. J. Wirz, Helv. Chim. Acta, 66, 1556 (1983).

21. T. Arai, O. Kikuchi, T. Karatsu, H. Sakuragi, and K. Tokumaru, to be published.

22. H. Hamaguchi, M. Tasumi, T. Karatsu, T. Arai, and K. Tokumaru, J. Am. Chem. Soc., 108, $1698(1986)$.

23. a. T. Arai, T. Karatsu, H. Sakuragi, and K. Tokumaru, Chem. Phys. Lett., submitted for publication.

b. T. Arai, T. Karatsu, H. Sakuragi, K. Tokumaru, N. Tamai, and I. Yamazaki, in preparation.

24. A. A. Gorman, I. Hamblett, M. Irvine, P. Raby, M. C. Standen, and S. Yeates, J. Am. Chem. Soc., 107, 4404 (1985).

25. W. G. Herkstroeter, J. Am. Chem. Soc., 97, 4161 (1975).

26. H. Misawa, T. Karatsu, T. Arai, $\mathrm{H}$. Sakuragi, and K. Tokumaru, Chem. Phys. Lett., in press.

27. O. L. J. Gijzeman, F. Kaufman, and G. Porter, J. Chem. Soc., Faraday Trans, 2, 69, 708 (1973).

28. A. A. Gorman and M. A. J. Rodgers, Chem. Phys. Lett., 120,58 (1985).

29. M. G. Rockley and K. Salisbury, J. $\frac{\text { Chem. }}{437}$ (1976) Perkin 2, 1582 (1973).

30. J. B. Birks, Chem. Phys. Lett., 38,437 (1976).

31. T. Arai, Y. Kuriyama, T. Karatsu, H. Sakuragi, K. Tokumaru, and S. Oishi, J. Photochem., 36,125 (1987).

32. T. Arai, T. Karatsu, Y. Kuriyama, T. Hiresaki, H. Okamoto, H. Zeng, H. Furuuchi, H. Sakuragi, and K. Tokumaru, presented at Symposium on Photochemistry, Sendai, August (1987), Abstracts, p. 153.

33. T. Hiresaki, Y. Kuriyama, T. Karatsu, T. Arai, H. Sakuragi, and K. Tokumaru, presented at Symposium on Photochemistry, Sendai, August (1987), Abstracts, p. 83.

34. H. Okamoto, T. Arai, H. Sakuragi and K. Tokumaru, presented at Symposium on Photochemistry, Sendai, August (1987), Abstracts, p. 249.

35. H. Zeng, T. Arai, H. Sakuragi, and K. Tokumaru, presented at Symposium on Photochemistry, Sendai, August (1987), Abstracts, p. 119.

36. T. Arai, Kagaku to Kogyo (Chemistry \& Industry), 41, 238 (1988).

37. T. W. Ebbesen and K. Tokumaru, App1. Opt., 25, 4618 (1986). 